\title{
Rancang Bangun Chatbot Helpdesk untuk Sistem Informasi Terpadu Universitas Sam Ratulangi
}

\author{
Ruspandi R. Benedictus, Hans Wowor, Alwin Sambul \\ Teknik Informatika Universitas Sam Ratulangi Manado, Indonesia. \\ ruspandireynaldi@gmail.com, hanswowor@unsrat.ac.id, asambul@gmail.com
}

\begin{abstract}
Abstrak - Universitas Sam Ratulangi sudah menggunakan teknologi informasi dalam bentuk aplikasi untuk mempermudah kegiatan civitas akademika. Aplikasi-aplikasi tersebut tergabung dalam Sistem Informasi Terpadu.

Layanan helpdesk merupakan hal yang pertama dicari oleh user ketika mengalami masalah atau memerlukan informasi dan bantuan atas suatu produk atau jasa. Akan tetapi, Universitas Sam Ratulangi belum mempunyai layanan helpdesk untuk memberikan pelayanan kepada user. Karena itu dibuatlah sebuah aplikasi chatbot helpdesk yang bisa menjawab pertanyaan-pertanyaan seputar penggunaan aplikasi-aplikasi dalam Sistem Informasi Terpadu.

Chatbot ini menggunakan teknologi web, algoritma bigram sebagai algoritma untuk pencocokan pola kalimat dan metode forward chaining sebagai metode penalaran ketika pertanyaan yang diberikan memerlukan kondisi-kondisi tertentu agar bisa dijawab. Metodologi pengembangan perangkat lunak yang digunakan adalah metode Prototyping dan pengujian aplikasi menggunakan metode Black Box.

Penelitian ini menghasilkan aplikasi Chatbot Helpdesk yang bisa membantu user dengan menjawab pertanyaan seputar penggunaan aplikasi-aplikasi dalam Sistem Informasi Terpadu Universitas Sam Ratulangi.
\end{abstract}

\section{Kata kunci : Helpdesk, Chatbot, Bigram, Forward Chaining, Inference Engine}

\section{PENDAHULUAN}

Universitas Sam Ratulangi (Unsrat) merupakan universitas yang sudah memanfaatkan teknologi informasi dalam beberapa proses bisnisnya. Semua teknologi tersebut tergabung dalam Sistem Informasi Terpadu (SIT) Unsrat. Dalam SIT Unsrat, tergabung sejumlah aplikasi, salah satu contohnya adalah Portal Akademik.

Aplikasi yang beragam serta banyaknya fungsionalitas yang ada, menyebabkan user memerlukan waktu untuk beradaptasi agar bisa menggunakan aplikasi-aplikasi tersebut dengan benar, apalagi bagi mahasiswa baru. Untuk Portal Akademik, walaupun sudah ada panduan tertulis yang bisa diunduh, itu tidak menjamin bahwa user dapat langsung bisa mengerti penjelasannya. Ketika ingin mendapatkan informasi mengenai aplikasi-aplikasi itu, user harus pergi ke lokasi tertentu dan hanya bisa pada jam kantor saja. Kurangnya informasi tentang penggunaan SIT menyebabkan user, terutama mahasiswa bertanya kepada mahasiswa lain sehingga informasi yang didapatkan bisa saja tidak akurat.
Dengan demikian, perlu dibangun sebuah aplikasi chatbot helpdesk yang bisa menjawab / memberikan informasi seputar penggunaan aplikasi-aplikasi tersebut kepada user. Dari hal tersebut maka penulis mengangkat judul "Rancang Bangun Chatbot Helpdesk untuk Sistem Informasi Terpadu Universitas Sam Ratulangi”.

\section{LANDASAN TEORI}

Chatbot yang dibuat merupakan aplikasi helpdesk bertipe Question Answering, sehingga bantuan yang ditawarkan adalah menjawab pertanyaan user. Chatbot ini menggunakan algoritma bigram sebagai algoritma untuk pattern matching, dan forward chaining inference engine sebagai metode penalaran jika untuk menjawab pertanyaan user memerlukan informasi tambahan.

Chatbot yang dibuat merupakan chatbot dengan pengetahuan yang bersifat close domain. Chatbot dibuat dengan menggunakan teknologi web. Untuk client side menggunakan HTML, CSS, dan jQuery sebagai library Javascript. Sedangkan untuk server side menggunakan bahasa pemrograman PHP dengan framework CodeIgniter. Proses pengembangan software menggunakan metode Prototyping dan pengujian menggunakan metode Black Box.

\section{A. Helpdesk}

Helpdesk merupakan struktur atau program yang menangani segala bentuk keluhan dari berbagai pihak dengan menyediakan layanan untuk memberi informasi dan solusi kepada user[1]. Salah satu kebutuhan user terhadap helpdesk adalah meminta informasi[2], sehingga helpdesk harus mempunyai pengetahuan terhadap suatu produk atau layanan yang diberikan.

Di Unsrat sendiri, terutama di Unit Pelaksana Teknis Teknologi Informasi dan Komunikasi (UPT-TIK), tidak ada helpdesk fisik yang mengarahkan user apabila mereka ingin mendapatkan bantuan teknis ataupun menanyakan informasi. Oleh karena itu, dibuat sistem helpdesk yang bisa mengotomatisasi jawaban atas pertanyaan-pertanyaan user dan bisa diakses kapan saja dan dimana saja.

\section{B. Chatbot}

Chatbot merupakan program komputer yang berinteraksi dengan user menggunakan bahasa natural. Teknologi chatbot pertama dimulai pada tahun 1960an. Tujuan pembuatan chatbot ini adalah pengujian apakah chatbot dapat menipu user agar mereka mengira sedang berkomunikasi dengan manusia[3]. Pengujian ini dikenal dengan nama "Turing Test".

Chatbot adalah sebuah program yang dapat melakukan obrolan dalam bahasa alami mengenai sebuah topik yang ada dalam model pengetahuan chatbot tersebut. Artinya, chatbot harus bisa mengenali dan merespon kata-kata 
yang diberikan user. Kemampuan chatbot dalam mengenali dan memberikan respons ditentukan oleh ruang lingkup dari pengetahuan chatbot. Terdapat 2 macam ruang lingkup dari chatbot, yaitu :

1. Open Domain. User dapat membawa arah percakapan kemana saja. Jumlah topik yang dibahas tidak terbatas. Dibutuhkan pengetahuan tentang dunia yang luas dalam basis pengetahuan agar bisa mengenali dan memberikan respon terhadap masukan user.

2. Close Domain. Chatbot dirancang untuk memenuhi tujuan yang spesifik. Basis pengetahuan chatbot hanya mencakup topik seputar tujuan chatbot[4]. Dalam penelitian ini, dibuat chatbot bertipe close domain sehingga hanya bisa mengenali dan merespon masukan seputar pengunaan SIT Unrat.

\section{Pattern Matching}

Pattern matching dalam ilmu komputer adalah kegiatan pemeriksaan serangkaian string atau karakter yang ada untuk menemukan pola yang konstituen antar string [5]. Salah satu algoritma dalam pattern matching adalah bigram. Algoritma ini membagi string menjadi bigram. Bigram adalah sepasang unit tertulis yang berurutan, berupa huruf, suku kata atau kata[6].

Contoh bigram adalah :

String: "saya"

Bigram: ‘"sa", “ay", "ya”\}

Kemudian, dengan menggunakan rumus sentence similarity measurement :

$$
\text { similarity }=\frac{\operatorname{count}\left(S_{1} \cap S_{2}\right)+\operatorname{count}\left(S_{2} \cap S_{1}\right)}{\operatorname{count}\left(S_{1}\right)+\operatorname{count}\left(S_{2}\right)}
$$

S1 adalah string pertama dan s2 adalah string kedua. Count(s1 กs2) adalah jumlah irisan antar bigram s1 dan s2. Count(s1) adalah jumlah bigram s1 dan count(s2) adalah jumlah bigram $\mathrm{s} 2$.

Algoritma ini digunakan pada tugas akhir ini untuk mencari pertanyaan dalam database yang paling mirip dengan pertanyaan yang dimasukkan oleh user. Jika ada, chatbot akan menampilkan pasangan jawaban dari pertanyaan yang ditemukan tersebut.

\section{Inference Engine}

Inference engine merupakan software yang menghasilkan fakta baru atau asosiasi dari informasiinformasi yang ada. Inference engine merupakan finite state machine yang terdiri dari 3 state, yaitu mencocokan rule, memilih rule, dan mengeksekusi rule[7]. Pada tahap pertama, chatbot akan memilih semua rule yang terpenuhi berdasarkan data yang dimasukkan oleh user. Rule-rule tersebut masuk dalam kelompok conflict set. Pada tahap kedua, chatbot akan menerapkan sejumlah aturan penyelesaian konflik sehingga didapatkan rule yang akan dieksekusi. Pada tahap ketiga, chatbot mengeksekusi rule yang terpilih pada tahap kedua.

\section{E. Forward Chaining}

Metode forward chaining merupakan sebuah penalaran yang akan mengevaluasi fakta terlebih dahulu dan kemudian menghasilkan kesimpulan berdasarkan fakta-fakta yang ada[8]. Pada tiap rule yang ada di database, akan diuji kondisi benar atau salah dan pada akhirnya akan menghasilkan kesimpulan berdasarkan rule-rule yang sudah dimasukkan dalam database. Metode penalaran forward chaining digunakan dalam tugas akhir ini untuk menentukan output dari pertanyaan yang memiliki beberapa kondisi yang dituangkan dalam rulerule. Setelah bertanya dan terdapat rule untuk pertanyaan itu, user harus menjawab pertanyaan tambahan sesuai rule yang ada. Lalu chatbot akan menggunakan inference engine forward chaining untuk menentukan output setelah terlebih dahulu memproses masukan serta input pertanyaan tambahan.

\section{F. Prototyping}

Prototyping merupakan sebuah paradigma pengembangan perangkat lunak yang menawarkan pendekatan yang paling baik dan membantu pengembang dan stakeholder untuk memahami lebih baik apa yang akan dikembangkan saat spesifikasi kebutuhan belum jelas[9]. Spesifikasi kebutuhan yang belum jelas biasanya terjadi ketika stakeholder maupun pengembang masih belum bisa mengidentifikasi secara detail spesifikasi yang rinci untuk fungsi-fungsi dan fitur-fitur, algoritma yang akan digunakan, maupun komponen-komponen lainnya seperti desain tampilan dan spesifikasi sistem.

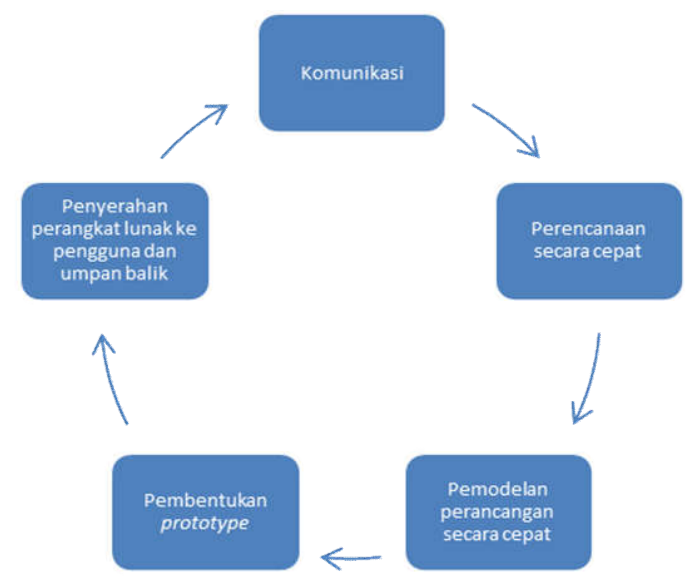

Gambar 1. Metode Prototype

\section{G. Black Box}

Pengujian black box merupakan pengujian dimana kasus uji didesain berdasarkan spesifikasi dan berfokus pada output yang dihasilkan sebagai respon dari input yang dipilih dan kondisi-kondisi eksekusi[10]. Kelebihan dari pengujian black box adalah :

1. Penguji tidak memerlukan pengetahuan akan bahasa pemrograman yang digunakan.

2. Membantu menemukan ambiguitas dan ketidakkonsistenan yang terjadi antara penguji dan pengembang.

\section{METODOLOGI PENELITIAN}

\section{A. Identifikasi Masalah}

Identifikasi masalah dari hasil observasi di Unsrat adalah sebagai berikut:

1. Sebagian mahasiswa yang bingung saat pertama 
kali menggunakan Portal Akademik Unsrat.

2. Kesulitan untuk mencari informasi mengenai penggunaan SIT Unsrat karena harus pergi ke lokasi tertentu dan pada jam kantor saja.

B. Pengumpulan Data

Metode pengumpulan data yang digunakan peneliti pada penelitian ini terdiri dari :

1. Studi Literatur

Menggunakan panduan yang ada di Buku Panduan Portal Akademik Unsrat.

2. Observasi

Observasi dilakukan dengan melihat keadaan lapangan di Unsrat, khususnya UPT-TIK dan survei di Forum Diskusi Portal Akademik Unsrat.

3. Kuisioner

Kuisioner disebarkan kepada 100 mahasiswa Unsrat.

4. Wawancara

Dilakukan wawancara dengan Kepala UPT-TIK Unsrat.

\section{Metode Pengembangan Perangkat Lunak}

Metode pengembangan perangkat lunak yang digunakan adalah metode Prototyping yang terdiri dari 5 tahap, yaitu Tahap Komunikasi, Tahap Perencanaan secara cepat, Tahap Pemodelan Perancangan secara cepat, Tahap Pembentukan Prototype, Tahap Penyerahan Sistem.

\section{Tahap Komunikasi}

Pada tahap ini dikumpulkan data melalui kuesioner tentang fitur apa saja pada Portal Akademik Unsrat yang masih sulit untuk digunakan. Pada kuesioner juga terdapat contoh pertanyaan-pertanyaan seputar Portal Akademik. Data juga diambil dari Buku Panduan Portal Akademik Unsrat sebagai panduan dasar untuk pengoperasian.

2. Tahap Perencanaan secara cepat

Pada tahap ini dilakukan perancangan cepat desain interface aplikasi web helpdesk dan alur kerja program.

3. Tahap Pemodelan Perancangan Secara Cepat Pada tahap ini dilakukan pemodelan perangkat lunak berdasarkan hasil desain dari tahap dua. Pemodelan tersebut mencakup Use Case Diagram, Flowchart dan Entity Relationship Diagram.

4. Tahap Pembentukan Prototype Pada tahap ini hasil pemodelan dituangkan dalam database dan kode sumber aplikasi.

5. Tahap Penyerahan Sistem/Perangkat lunak Prototype yang berhasil dibangun akan diserahkan kepada user. Setelah pengujian selesai, user akan memberikan umpan balik mengenai kekurangan aplikasi. Perbaikan chatbot dilakukan berdasarkan hasil umpan balik.

D. Perancangan Perangkat Lunak

Perancangan yang dibuat mencakup Use Case Diagram, Entity Relationship Diagram, flowchart algoritma bigram, dan flowchart alur dialog chatbot.

\section{Use Case Diagram}

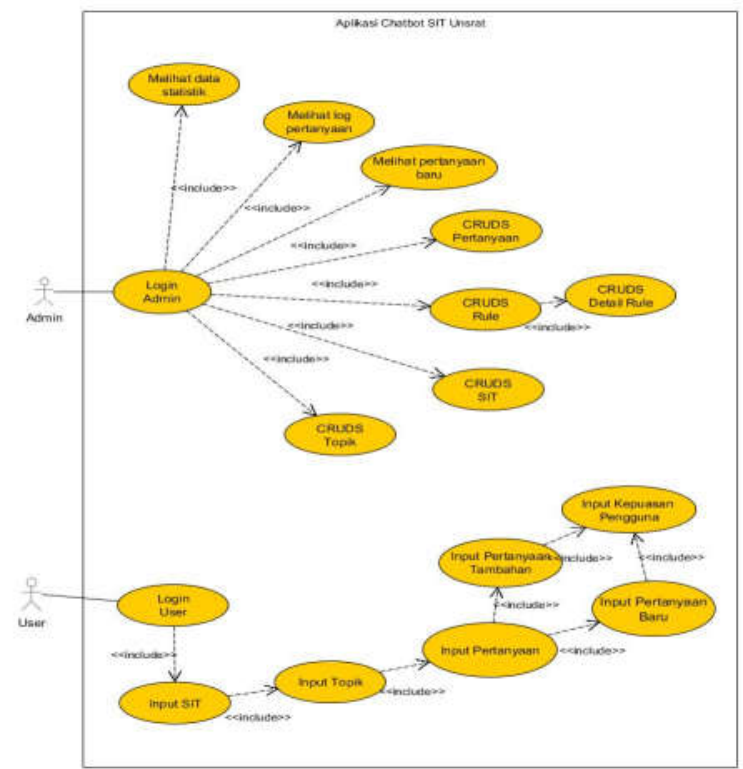

Gambar 2. Use Case Diagram

Dari Gambar 2 bisa dilihat bahwa administrator bisa melakukan manajemen terhadap pertanyaan, rule, daftar SIT, topik serta melihat statistik untuk mempermudah penambahan data pada database chatbot. User hanya bisa menginputkan pertanyaan dan diakhir sesi ada permintaan penilaian kualitas chatbot.

Entity Relationship Diagram

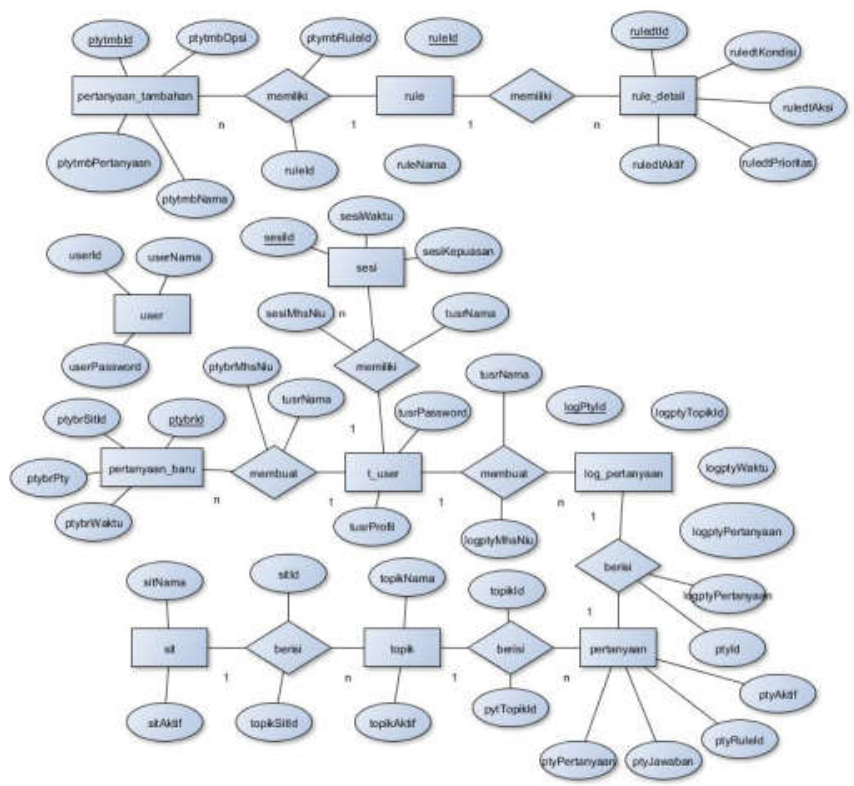

Gambar 3. Entity Relationship Diagram 
Pada Gambar 3 dapat dilihat rancangan struktur database chatbot yang akan diimplementasikan.

\section{Flowchart Algoritma Bigram}

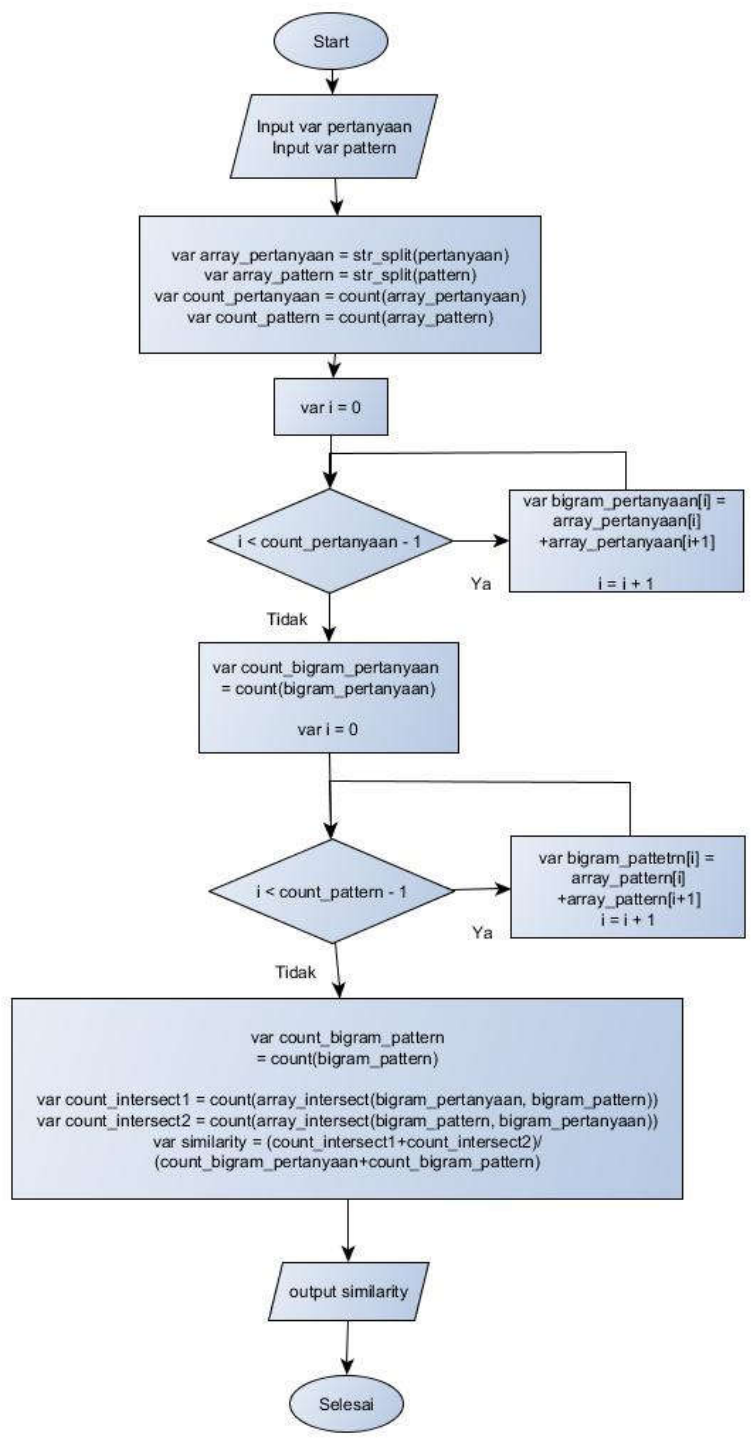

Gambar 4. Flowchart algoritma bigram

Gambar 4 merupakan flowchart algoritma bigram yang dibuat berdasarkan persamaan (I).

Langkah awal pada algoritma bigram adalah input dua variabel string yang akan dibandingkan, yaitu pertanyaan dan pattern. Variabel pertanyaan merupakan string pertanyaan yang diinputkan oleh user, sedangkan variabel pattern merupakan pertanyaan yang ada di database. Kedua string tersebut dipecah menggunakan fungsi str_split sehingga menghasilkan array yang beranggotakan huruf-huruf dari masing-masing string.

Sehingga hasilnya adalah dua buah array yang berisikan pecahan huruf dari masing-masing string, yaitu array_pertanyaan dan variabel array_pattern. Jumlah anggota masing-masing array juga dihitung dan dimasukkan dalam variabel count pertanyaan dan count pattern.

Langkah berikutnya adalah melakukan perulangan sebanyak jumlah anggota array-1 untuk masing-masing array. Akan dibuat dua buah array baru, yaitu bigram_pertanyaan dan bigram_pattern yang berisi bigram dari array_pertanyaan dan array_pattern.

Jumlah anggota bigram_pertanyaan dan bigram_pattern juga akan dihitung dan dimasukkan dalam variabel count_bigram_pertanyaan dan count_bigram_pattern.

Langkah selanjutnya adalah menghitung jumlah irisan antara dua bigram_pertanyaan dan bigram_pattern yang disimpan dalam variabel count intersectl dan count_intersect2. Lalu nilai kemiripan dihitung berdasarkan jumlah count_intersect1 dan count_intersect2 dibagi dengan jumlah count_bigram_pertanyaan dan count bigram pattern. Keluaran dari proses ini adalah nilai kemiripan tersebut.

\section{Alur Dialog Chatbot}

Chatbot yang dibuat memiliki alur dialog sebagai berikut:

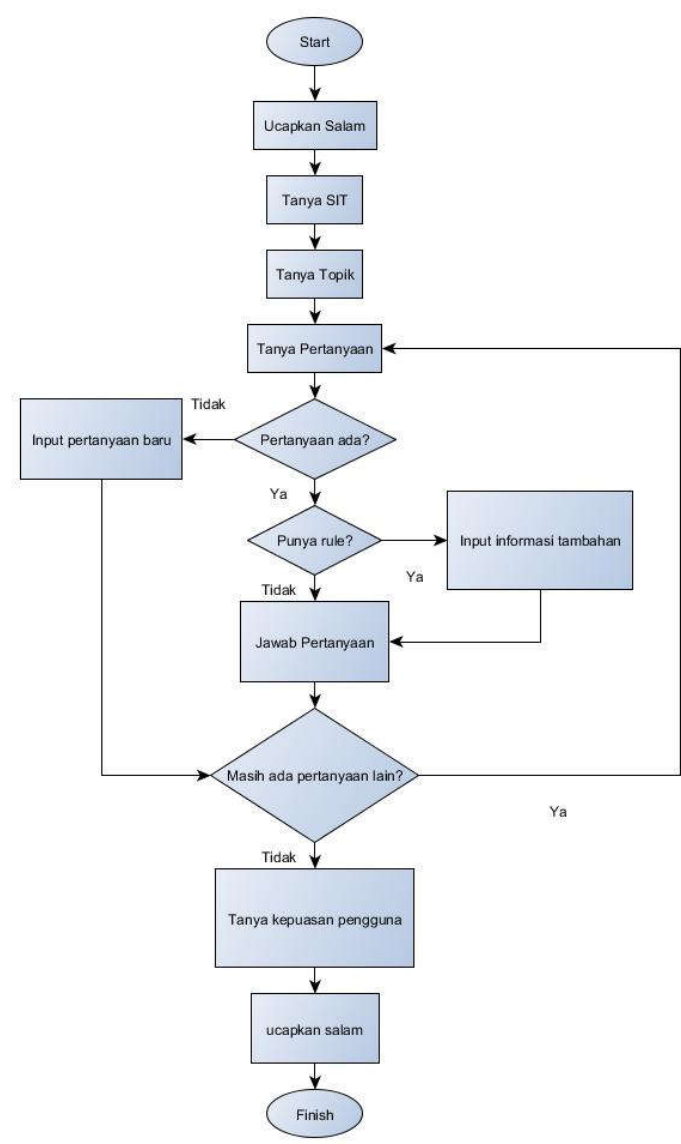

Gambar 5. Alur dialog chatbot

\section{HASIL DAN PEMBAHASAN}

\section{A. Implementasi Database}

Pada tahap ini peneliti membangun database berdasarkan rancangan Entity Relationship Diagram yang telah dibuat.

Tabel 1. Tabel log_pertanyaan

\begin{tabular}{|c|c|c|c|}
\hline \multicolumn{4}{|c|}{$\log$ pertanyaan } \\
\hline Nama Kolom & Tipe Data & Panjang & PK \\
\hline logptyId & int & 11 & Ya \\
\hline logptyTopikId & int & 11 & \\
\hline
\end{tabular}




\begin{tabular}{|c|c|c|c|} 
logptyPertanyaan & text & & \\
\hline logptyMhsNiu & varchar & 20 & \\
\hline logptyWaktu & datetime & & \\
\hline
\end{tabular}

Tabel 2. Tabel pertanyaan

\begin{tabular}{|c|c|c|c|}
\hline \multicolumn{4}{|c|}{ pertanyaan } \\
\hline Nama Kolom & Tipe Data & Panjang & PK \\
\hline ptyId & int & 11 & Ya \\
\hline ptyTopikId & int & 11 & \\
\hline ptyPertanyaan & text & & \\
\hline ptyJawaban & text & & \\
\hline ptyRuleId & int & 11 & \\
\hline ptyAktif & tinyint & 1 & \\
\hline
\end{tabular}

Tabel 3. Tabel pertanyaan_baru

\begin{tabular}{|c|c|c|c|}
\hline \multicolumn{4}{|c|}{ pertanyaan_baru } \\
\hline Nama Kolom & Tipe Data & Panjang & PK \\
\hline ptybrId & int & 11 & Ya \\
\hline ptybrSitId & int & 11 & \\
\hline ptybrTopikId & int & 11 & \\
\hline ptybrPty & text & & \\
\hline ptybrMhsNiu & varchar & 20 & \\
\hline ptybrWaktu & datetime & & \\
\hline
\end{tabular}

Tabel 4. Tabel pertanyaan_tambahan

\begin{tabular}{|c|c|c|c|}
\hline \multicolumn{4}{|c|}{ pertanyaan_tambahan } \\
\hline Nama Kolom & Tipe Data & Panjang & PK \\
\hline ptytmbId & int & 11 & Ya \\
\hline ptytmbRuleId & int & 11 & \\
\hline ptytmbNama & varchar & 25 & \\
\hline ptytmbPertanyaan & varchar & 255 & \\
\hline ptytmbOpsi & int & 255 & \\
\hline
\end{tabular}

Tabel 5. Tabel rule

\begin{tabular}{|c|c|c|c|}
\hline \multicolumn{4}{|c|}{ rule } \\
\hline Nama Kolom & Tipe Data & Panjang & PK \\
\hline ruleId & int & 11 & Ya \\
\hline ruleNama & varchar & 50 & \\
\hline
\end{tabular}

Tabel 6. Tabel rule_detail

\begin{tabular}{|c|c|c|c|}
\hline \multicolumn{4}{|c|}{ rule_detail } \\
\hline Nama Kolom & Tipe Data & Panjang & PK \\
\hline ruledtId & int & 11 & Ya \\
\hline ruledtRuleId & int & 11 & \\
\hline ruledtKondisi & varchar & 255 & \\
\hline ruledtAksi & text & 255 & \\
\hline ruledtPrioritas & tinyint & 2 & \\
\hline ruledtAktif & tinyint & 1 & \\
\hline
\end{tabular}

Tabel 7. Tabel sesi

\begin{tabular}{|c|c|c|c|}
\hline \multicolumn{4}{|c|}{ sesi } \\
\hline Nama Kolom & Tipe Data & Panjang & PK \\
\hline sesild & varchar & 32 & Ya \\
\hline sesiMhsNiu & varchar & 20 & \\
\hline sesiWaktu & datetime & & \\
\hline sesiKepuasan & tinyint & 1 & \\
\hline
\end{tabular}

Tabel 8. Tabel SIT

\begin{tabular}{|c|c|c|c|}
\hline \multicolumn{4}{|c|}{ Sit } \\
\hline Nama Kolom & Tipe Data & Panjang & PK \\
\hline sitId & int & 11 & Ya \\
\hline sitNama & varchar & 50 & \\
\hline sitAktif & tinyint & 1 & \\
\hline
\end{tabular}

Tabel 9. Tabel Topik

\begin{tabular}{|c|c|c|c|}
\hline \multicolumn{4}{|c|}{ Topic } \\
\hline Nama Kolom & Tipe Data & Panjang & PK \\
\hline topikId & int & 11 & Ya \\
\hline topikSitId & int & 11 & \\
\hline topikNama & varchar & 50 & \\
\hline topikAktif & tinyint & 1 & \\
\hline
\end{tabular}

Tabel 10. Tabel user

\begin{tabular}{|c|c|c|c|}
\hline \multicolumn{4}{|c|}{ user } \\
\hline Nama Kolom & Tipe Data & Panjang & PK \\
\hline usrId & int & 11 & Ya \\
\hline usrNama & varchar & 20 & \\
\hline usrPassword & varchar & 255 & \\
\hline
\end{tabular}

Tabel sit memuat daftar aplikasi yang bisa ditanyakan kepada chatbot. Tabel topik memuat daftar topik yang tersedia pada masing-masing aplikasi pada tabel sit. Sedangkan tabel pertanyaan memuat daftar pertanyaan yang tersedia pada masing-masing topik. Pada tabel sit, topik dan pertanyaan memiliki kolom untuk menentukan pertanyaan tersebut aktif atau tidak. Sehingga administrator nantinya bisa mengaktifkan atau menonaktifkan suatu SIT, topik, atau pertanyaan.

Pada tabel pertanyaan terdapat jawaban dari masingmasing pertanyaan dan juga rule, jika pertanyaan tersebut mempunyai rule. Suatu pertanyaan memiliki rule apabila pertanyaan tersebut memerlukan informasi tambahan untuk dijawab. Daftar rule yang tersedia dapat dilihat pada tabel rule. Setiap rule memiliki pertanyaan tambahan yang ada pada tabel pertanyaan_tambahan dan harus dijawab oleh user dan jawaban tersebut akan diproses berdasarkan kondisi yang ada pada tabel rule_detail. Tabel rule_detail berisi daftar kondisi jawaban user atas pertanyaan tambahan yang mungkin dan juga aksi (jawaban) yang sesuai berdasarkan kondisi yang ada.

Tabel user memuat data administrator. Tabel sesi memuat data sesi login beserta waktu login dan juga 
kepuasan dari tiap sesi yang nantinya akan digunakan untuk menilai kualitas chatbot. Tabel t user memuat data user yang bisa login yang diambil dari database akademika_portal Unsrat, sehingga setiap user dapat login menggunakan username dan password Portal Akademik mereka.

Tabel log_pertanyaan memuat data semua pertanyaan yang pernah diajukan oleh user. Tabel log ini juga berisi topik pertanyaan. Sehingga dari data pada tabel ini dapat terlihat pertanyaan serta topik mana yang paling banyak dan paling sedikit ditanyakan.

Tabel pertanyaan_baru merupakan tabel untuk menampung pertanyaan user yang belum ada di tabel pertanyaan. Nantinya pertanyaan yang ada pada pertanyaan_tambahan akan ditambahkan oleh administrator ke tabel pertanyaan.

\section{B. Implementasi Sistem}

Pada tahap ini, rancangan flowchart dan alur dialog chatbot dituangkan dalam kode sumber dan dibuat antarmuka, baik untuk administrator maupun untuk user.

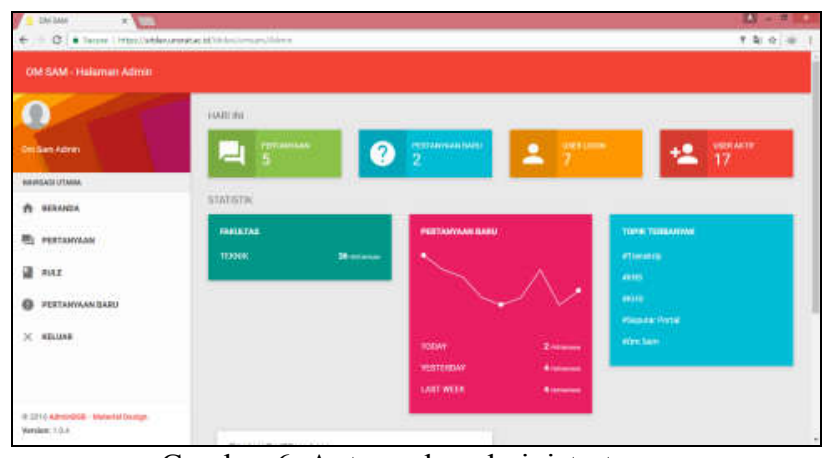

Gambar 6. Antarmuka administrator

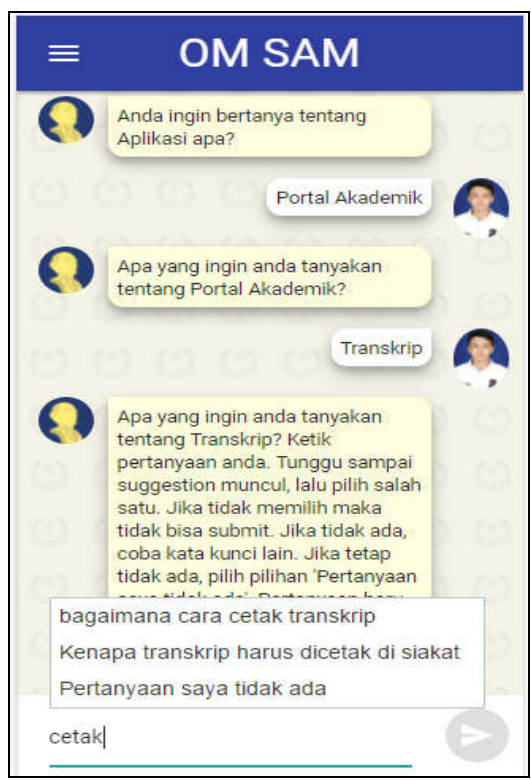

Gambar 7. Antarmuka user

\section{Pengujian Sistem}

Pada tahap ini digunakan metode pengujian Black Box. Disiapkan 16 kasus uji, dan setelah dilakukan pengujian, aplikasi berhasil lolos $100 \%$ dari 16 kasus uji tersebut.
Tabel 11. Hasil pengujian Black Box

\begin{tabular}{|c|c|c|c|}
\hline No. & $\begin{array}{l}\text { Komponen } \\
\text { Pengujian }\end{array}$ & Masukan & Status \\
\hline 1 & Login & $\begin{array}{c}\text { User memasukkan } \\
\text { NIP/NIM }\end{array}$ & Diterima \\
\hline 2 & $\begin{array}{c}\text { Operasi } \\
\text { CRUD } \\
\text { untuk } \\
\text { pertanyaan }\end{array}$ & $\begin{array}{l}\text { Admin menambah, } \\
\text { mengubah dan } \\
\text { menghapus pertanyaan }\end{array}$ & Diterima \\
\hline 3 & $\begin{array}{c}\text { Operasi } \\
\text { CRUD } \\
\text { untuk rule }\end{array}$ & $\begin{array}{c}\text { Administrator } \\
\text { menambah, mengubah } \\
\text { dan menghapus rule }\end{array}$ & Diterima \\
\hline 4 & $\begin{array}{c}\text { Operasi } \\
\text { CRUD } \\
\text { untuk SIT }\end{array}$ & $\begin{array}{c}\text { Administrator } \\
\text { menambah, mengubah } \\
\text { dan menghapus SIT }\end{array}$ & Diterima \\
\hline 5 & $\begin{array}{l}\text { Operasi } \\
\text { CRUD } \\
\text { untuk } \\
\text { Topik }\end{array}$ & $\begin{array}{c}\text { Administrator } \\
\text { menambah, mengubah } \\
\text { dan menghapus topik }\end{array}$ & Diterima \\
\hline 6 & $\begin{array}{c}\text { Operasi } \\
\text { CRUD } \\
\text { untuk user }\end{array}$ & $\begin{array}{c}\text { Administrator } \\
\text { menambah, mengubah } \\
\text { dan menghapus } u \text { ser }\end{array}$ & Diterima \\
\hline 7 & $\begin{array}{c}\log \\
\text { Pertanyaan }\end{array}$ & $\begin{array}{c}\text { User menanyakan } \\
\text { pertanyaan }\end{array}$ & Diterima \\
\hline 8 & $\begin{array}{l}\text { Pertanyaan } \\
\text { tidak } \\
\text { terjawab }\end{array}$ & $\begin{array}{c}\text { User menanyakan } \\
\text { pertanyaan yang tidak } \\
\text { bisa dijawab oleh chatbot }\end{array}$ & Diterima \\
\hline 9 & $\begin{array}{c}\text { Statistik } \\
\text { penggunaa } \\
\mathrm{n}\end{array}$ & $\begin{array}{c}\text { User menanyakan } \\
\text { pertanyaan baik yang } \\
\text { bisa dijawab maupun } \\
\text { tidak }\end{array}$ & Diterima \\
\hline 10 & $\begin{array}{c}\text { Kebenaran } \\
\text { jawaban }\end{array}$ & $\begin{array}{c}\text { User menanyakan } \\
\text { pertanyaan }\end{array}$ & \\
\hline 10.1 & & Siapa nama kamu? & Diterima \\
\hline 10.2 & & Siapakah nama anda??? & Diterima \\
\hline 10.3 & & $\begin{array}{c}\text { bagaimana cara } \\
\text { menghapus mata kuliah } \\
\text { di krs }\end{array}$ & Diterima \\
\hline 10.4 & & $\begin{array}{c}\text { bagaimana cara } \\
\text { menambah mata kuliah } \\
\text { di krs }\end{array}$ & Diterima \\
\hline 10.5 & & bagaimana cara print khs & Diterima \\
\hline
\end{tabular}




\section{A. Kesimpulan}

\section{PENUTUP}

Berdasarkan analisis, perancangan, implementasi dan pengujian yang telah dilakukan terhadap aplikasi chatbot, dapat diambil kesimpulan sebagai berikut :

1. Aplikasi Chatbot sebagai helpdesk telah berhasil dibangun dengan menggunakan algoritma Bigram dan Forward Chaining.

2. Aplikasi Chatbot dapat menjawab pertanyaan sesuai dengan yang diharapkan (pertanyaan yang sudah ada dalam database), sehingga dapat membantu user untuk menjawab pertanyaan seputar Portal Akademik.

B. Saran

1. Agar pihak universitas dapat dengan cepat dan tepat tanggap menambah pengetahuan chatbot apabila ada pertanyaan yang tidak bisa terjawab, karena keberhasilan chatbot sangat bergantung pada hal itu, sehingga perlahan-lahan pengetahuannya akan lebih baik.

2. Untuk penelitian selanjutnya agar menambahkan dialog manager sehingga lebih mudah mengatur jalannya percakapan serta respon-respon standar yang dihasilkan chatbot.

3. Menambahkan basis pengetahuan untuk SIT dan topik lainnya.

4. Melakukan pengujian di Unsrat.

\section{DAFTAR PUSTAKA}

[1] Manopo, R. I. 2016. "Perancangan Aplikasi Help Desk di UPT-TIK Unsrat", Tekno. vol. 8. no.1, 2016.

[2] Gibson, Darril. 2015. Effective Help Desk Specialist Skills. USA: Pearson Education, Inc.

[3] Shawar, A. \& Atwell, B. 2007. "Chatbot: Can They Serve as Natural Language Interfaces to QA Corpus?", LDV Forum 2007 - Band 22(1) 31-50.

[4] Britz, Denny. 2016. "Deep Learning for Chatbots, Part 1 - Introduction” [Online]. Available: http://www.wildml.com/2016/04/deep-learning-forchatbots-part-1-introduction. Diakses tanggal 12 Juni 2017.

[5] Dewi, A. \& Setiaji, B. 2014. "Pemanfaatan SentenceSimilarity Measurement untuk Proses Pencarian Pola pada Chatbot Berbasis Pattern-Matching," Seminar Nasional Teknologi Informasi dan Multimedia 2014, ISSN : 2302-3805, 8 Februari 2014.

[6] Oxford Living Dictionaries [Online].Available: https:/en.oxforddictionaries.com/definition/bigram. Diakses tanggal 12 Juni 2017

[7] Singh, Swapna \& Karwayun, Ragini. 2010. "A Comparative Study of Inference Engines" Seventh International Conference on Information Technology 2010.

[8] Baiti, Zifora.,Nugroho, Fresy. 2013. "Aplikasi Chatbot IM3 untuk Informasi Jurusan Teknik Informatika Berbasis Sistem Pakar menggunakan Forward Chaining”, MATICS vol.5 no.3, September 2013.

[9] Pressman, Roger. 2012. Rekayasa Perangkat Lunak 7th ed. Yogyakarta: ANDI.

[10] Nidhra, Srinivas dan Dondeti, Jagruthi. 2012, Black Box And White Box Testing Techniques -A Literature
Review, International Journal of Embedded Systems and Applications (IJESA) Vol.2, No.2, 8-9.

[11] Wickramanayake, Kamal. "PhpExpertSystem" [Online]. Available:

http://www.deadschool.com/phpexpertsystem. Diakses tanggal 12 Juni 2017.

\section{SEKILAS TENTANG PENULIS}

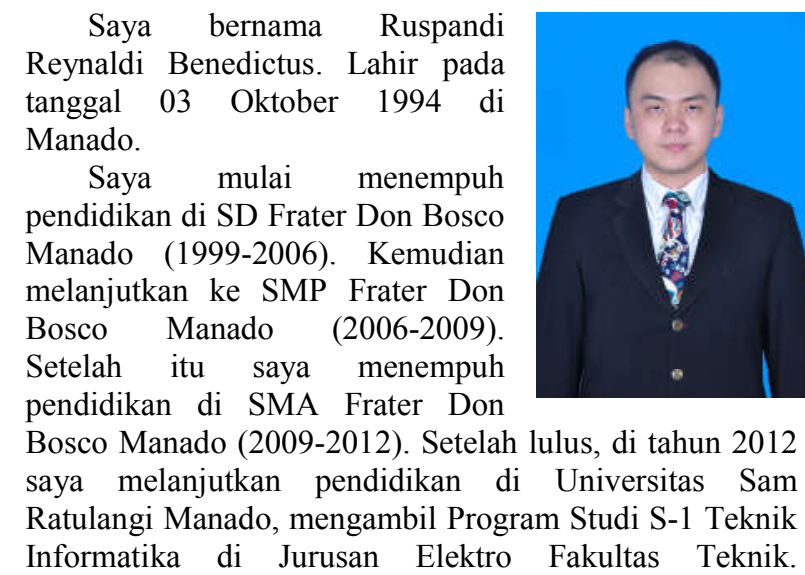

